\title{
Autosomal spastic paraplegia type 58
}

INSERM

\section{Source}

INSERM. (1999). Orphanet: an online rare disease and orphan drug data base. Autosomal spastic paraplegia type 58. ORPHA:397946

Autosomal recessive spastic paraplegia type 58 is a rare, complex subtype of hereditary spastic paraplegia characterized by variable onset of slowly progressive lower limb spasticity and weakness and prominent cerebellar ataxia, associated with gait disturbances, dysarthria, increased deep tendon reflexes and extensor plantar responses. Additional features may include involuntary movements (i.e. clonus, tremor, fasciculations, chorea), decreased vibration sense, oculomotor abnormalities (e.g. nystag mus) and distal amyotrophy in the upper and lower limbs. 